\title{
Revitalisasi Seni Budaya Wayang melalui Tayangan Televisi
}

\author{
Agus Maladi Irianto \\ Fakultas Ilmu Budaya, Universitas Diponegoro \\ ami.fibundip.@gmail.com
}

\begin{abstract}
The development of traditional art is the development of artistic values and art appreciation in order to increase the artist and community's friendship. Ideally the arts as part of the national culture derive its meaning in terms of understanding and appreciation of cultural values. Therefore, to improve the resilience of the nation's culture, then the national development needs to be dotted from the efforts of art development that can give birth to "cultural value-added". Artistic gifts (local and national) are essentially necessary, because they are rooted in the culture of society. However, it is possible for decomposition, reconstruction, recoreography, renovation, revitalization, refunctionalization, along with improvisations with various ornaments. This is where local art becomes cultural property and socio-cultural "capital" of society. For this reason, a strategy is needed so that regional art can be placed as a means of creating a nation's cultural resilience. One of them is to revitalize the art of wayang culture through television shows.
\end{abstract}

Keywords: traditional arts, cultural endurance, and revitalization.

\section{Intisari}

Pengembangan kesenian tradisonal adalah pembangunan nilai-nilai seni dan apresiasi seni demi meningkatkan kemartabatan seniman dan masyarakat. Idealnya kesenian sebagai bagian dari kebudayaan nasional memperoleh maknanya dalam kaitan dengan pemahaman dan apresiasi nilai-nilai kultural. Oleh karena itu, untuk meningkatkan ketahanan budaya bangsa, maka pembangunan nasional perlu bertitik-tolak dari upaya-upaya pengembangan kesenian yang mampu melahirkan "nilai-tambah kultural". Pakem-pakem kesenian (lokal dan nasional) pada dasarnya tetap diperlukan, karena ia berakar dalam budaya masyarakat. Akan tetapi, ia dimungkinkan untuk dekomposisi, rekonstruksi, rekoreografi, renovasi, revitalisasi, refungsionalisasi, disertai improvisasi dengan aneka hiasan. Di sinilah kesenian daerah menjadi kekayaan budaya dan "modal sosial-kultural" masyarakat. Untuk itulah,diperlukan sebuah strategi agar kesenian daerah dapat ditempatkan sebagai sarana menciptakan ketahanan budaya suatu bangsa. Salah satu di antaranya adalah dengan melakukan revitalitasi seni budaya wayang melalui tayangan televisi.

Kata kunci: kesenian tradisional, ketahanan budaya, dan revitalisasi. 


\section{Pendahuluan}

Kehadiran era globalisasi tak bisa dihindari, namun hak hidup dan ketahanan kebudayaan lokal harus tetap dijaga. Untuk itu, ketahanan kebudayaan harus selalu diartikan secara dinamis, di mana unsur-unsur kebudayaan dari luar ikut memperkokoh unsur-unsur kebudayaan lokal. Untuk itu, perlu kita kemukakan bahwa proses globalisasi, yang dikatakan dapat mempertajam "clash of civilizations", dan meminjam istilah Samuel Huntington - juga dapat mengakibatkan perusakan berat terhadap peradaban. Kemasyarakatan dan kesadaran etnis (exacerbation of civilizational, societal and ethnic self-consciousness), tidak perlu mengakibatkan pelumpuhan yang memarginalisasi eksistensi bangsa ini.

Dengan demikian dapat dikatakan bahwa pengembangan kesenian tradisional adalah pembangunan nilai-nilai seni dan apresiasi seni demi meningkatkan kemartabatan seniman dan masyarakat. Dalam pembangunan nasional, idealnya kesenian sebagai bagian dari kebudayaan nasional memperoleh maknanya dalam kaitan dengan pemahaman dan apresiasi nilai-nilai kultural. Oleh karena itu, untuk meningkatkan ketahanan budaya bangsa, maka pembangunan nasional perlu bertitiktolak dari upaya-upaya pengembangan kesenian yang mampu melahirkan "nilaitambah kultural".

Pakem-pakem kesenian (lokal dan nasional) pada dasarnya tetap diperlukan, karena ia berakar dalam budaya masyarakat. Akan tetapi, ia dimungkinkan untuk dekomposisi, rekonstruksi, rekoreografi, renovasi, revitalisasi, refungsionalisasi, disertai improvisasi dengan aneka hiasan. Sentuhan-sentuhan nilai-nilai dan nafas baru, perlu juga dikembangkan demi mengundang apresiasi dan menumbuhkan sikap pembaharuan dan pengayaan karya-karya seni. Di sinilah awal dari kesenian daerah menjadi kekayaan budaya dan "modal sosial-kultural” masyarakat.

Di sisi lain kita harus menyadari bahwa kesenian daerah (tradisional) pada dasarnya adalah anonim. Bahkan, lebih jauh lagi ia juga tak bisa dibatasi atas klaim wilayah. Ia menjadi tak terbatasi oleh garis yang pasti (borderless). Untuk itulah, jika kesenian ditempatkan sebagai sarana menciptakan ketahanan budaya suatu bangsa maka persoalan makna ketahanan budaya tersebut harus disikapi sebagai ketahanan nasional.

Seumpama kesenian dapat dianalogkan dengan ekonomi misalnya, maka pembangunan ekonomi yang bermakna sebagai upaya untuk meningkatkan "nilai- 
tambah ekonomi", maka pembangunan kesenian dan kebudayaan akan bermakna sebagai upaya meningkatkan "nilai-tambah kultural". Nilai tambah kultural pada dasarnya juga memuat makna nilai-tambah kemartabatan, nilai-tambah kebanggaan, nilai-tambah jatidiri dan nilai-tambah akal budi. Hal ini erat kaitannya dengan apa yang dicita-citakan oleh kemerdekaan bangsa ini, yaitu cita-cita untuk "mencerdaskan kehidupan bangsa".

Mencerdaskan kehidupan bangsa bukanlah makna yang berdasarkan pada konsepsi iptek atau pun konsepsi biologi-genetika, melainkan merupakan suatu konsepsi budaya. Dengan demikian "mencerdaskan kehidupan bangsa" merupakan upaya untuk meningkatkan kekayaan batin, meningkatkan kadar budaya bangsa, kadar kemadanian, sebagai suatu proses humanisasi mencapai keadiluhungan yang mengungguli basic instincts, untuk mengangkat harkat dan derajat insani dari bangsa kita.

Untuk itu merevitaliasi kesenian trtadisonal menjadi salah satu strategi yang efektif untuk meningkatkan ketahanan budaya bangsa, bahkan pembangunan nasional idealnya bertitik-tolak dari upaya-upaya pengembangan kesenian tradisional yang mampu melahirkan "nilai-tambah kultural". Untuk itulah,diperlukan sebuah strategi agar kesenian tradisional dapat ditempatkan sebagai sarana menciptakan ketahanan budaya suatu bangsa.

Seni budaya wayang misalnya, selama ini sudah cukup familiar dikenal oleh masyarakat khususnya masyarakat Jawa Tengah. Akan tetapi, seiiring dengan perkembangan zaman, seni budaya yang sudah cukup lama menjadi bagian dari kebutuhan integratif masyarakat Jawa Tengah kini lambat 1;aun justru semakin ditinggal audiencenya. Durasi pertujukan yang lama, penyajian pertunjukan yang monoton, serba bahsa yang disampaikan yang kurang komunkatif membawa konsekuensei kesenian yang telah menjadi ikon Orang Jawa itu justru ditinggalkan masyarakatnya

Daya tarik sejumlah tayangan televisi yang lebih variatif dianggap lebih memikat dibandingkan seni budaya wayang tersebut. Dari sinilah, revitalisasi kesenian tradisional sangat diperlukan terutama tetap mempertahankan media ekspresi wayang namun mampu mengitegrasikan tuntutan tayangan televise yang dinamis. Singkat kata, kegiatan berupa revitalsasi seni budaya melalui tayangan pesawat televisi sangat strategis. 
Untuk itulah tujuan tulisan berikut beusaha untuk mengartikulasikan kesenian tradisional sejalan dengan tuntutan perkembangan sosial, sehingga mudah beradaptasi dan mendorong kepekaan umum terhadap nilai-nilai keanggunan seni. Di samping itu, mendorong dinamika seni menjadi kreatif dan menjadi kelengkapan kehidupan sehari-hari, serta menjadikannya semacam way of life.

\section{Hasil dan Pembahasan}

Untuk menjelaskan lebih lanjut tentan revitslisasi, kiranya perlu adanya pertimbsng sebsgai berikut: Pertama, revitaliasi kesenian tradisional - terutama seni budaya wayang - menjadi salah satu strategi yang efektif untuk meningkatkan ketahanan budaya bangsa, bahkan pembangunan nasional idealnya bertitik-tolak dari upayaupaya pengembangan kesenian tradisional yang mampu melahirkan "nilai-tambah kultural".

Kedua, seni budaya wayang selama ini dikenal sebagai kesenian yang hanya mempertahankan pakem-pakem yang kaku tetapi kurang beradaptasi dengan perkembangan zaman dan tuntutan audience-nya. Pakem-pakem itu memang tetap diperlukan, karena ia berakar dalam budaya masyarakat, namun ia dimungkinkan untuk dekomposisi, rekonstruksi, rekoreografi, renovasi, revitalisasi, refungsionalisasi, disertai improvisasi dengan aneka hiasan.

Ketiga, strategi dekomposisi, rekonstruksi, rekoreografi, renovasi, revitalisasi, refungsionalisasi, dan improvisasi pada dasarnya menciptakan sentuhan-sentuhan nilai-nilai baru. Sentuhan-sentuhan nilai-nilai dan nafas baru, perlu juga dikembangkan demi mengundang apresiasi dan menumbuhkan sikap pembaharuan dan pengayaan karya-karya seni.

Keempat, untuk menumbuhkan sikap pembaharuan dan pengayaan karya-karya seni, salah satu di antaranya dengan kemasan audiovisual. Kemasan audio visual yang dimaksud adalah dengan menyajikan pertunjukan wayang dalam program tayangan televisi.

Kelima, menyajikan pertunjukan wayang dalam program tayangan televisi. di satu sisi bisa dijadikan strategi agar kesenian tradisonal dapat ditempatkan sebagai sarana menciptakan ketahanan budaya suatu bangsa. Sedangkan di sisi lain kemasan audio visual ini merupakan langkah efektif dalam rangka revitalitasi seni budaya. Dengan sejumlah argumentsi tersebut, harus diakui bahwa keberadaan 
tayangan cara dari sejumlah stasiun TV, sangat efektif untuk mendesiminasikan kesenian tradisional secama wayang ini. Tayangan acara televise pada dasarnya memuat strategi komunikasi agar mampu memelihara atau mengubah sikap atau pendapat sasaran demi kepentingan sumber pembuat strategi. Sehingga, dapat dikatakan bahwa televisi ini cenderung mengajak audience-nya agar patuh kepada pihak yang menguasai modal komunikasi, baik dalam konteks politik maupun ekonomi (Fiske, 1987).

Sejumlah penayangan melalui stasiun televisi sangat strategis dan efektif untuk mempengaruhi audience-nya. Pada pemerintahan Orde Baru misalnya, TVRI sebagai satu-satunya stasiun televisi - justru dijadikan alat propaganda pemerintah yang strategis dan efektif. Pada waktu itu, pemerintahan Orde Baru melalui Departemen Penerangan (Deppen) RI begitu menguasai dan mengendalikan media penyiaran televisi dalam setiap isi tayangannya. Bahkan menurut Kitley (2000), begitu berpengaruhnya media televisi, sehingga pemerintah Orde Baru turut campur tangan hingga penyusunan program, dalam rangka menyampaikan gagasan politik dan kebudayaan. Demikian juga yang diungkapkan Sen \& Hill (2001), Orde Baru mendefinisikan media sebagai kendaraan bagi terciptanya "kebudayaan nasional"

Sedangkan, pada perkembangan sekarang ini, campur tangan negara dalam pengendalian media penyiaran televisi tidak sekuat cengkeraman Deppen RI pada pemerintahan Orde Baru. Saat ini, dominasi negara - baik melalui Departemen Komunikasi dan Informatika (Depkominfo) maupun Komisi Penyiaran Indonesia (KPI) dalam rangka meregulasi media penyiaran televisi tidak lagi sekuat pemerintahan Orde Baru. Dalam perkembangan sekarang ini yang ditandai dengan munculnya para pemodal yang menguasai industri penyiaran televisi di Indonesia, telah terjadi cultural transgression akibat mitos-mitos bentukan mereka yang diekspresikan melalui media yang mereka miliki.

Bertolak dari kenyataan tersebut, dapat diyakini bahwa sajian acara yang "bertarung" lebih dari 15 jam dalam sehari itu, ternyata melibatkan sejumlah kepentingan. Ia tidak saja semata-mata atas kepentingan stasiun yang mempunyai jam siaran atau kepentingan negara yang berwenang melakukan regulasi siaran, tetapi juga melibatkan kepentingan sejumlah institusi lain. Sebut saja, rumah produksi, lembaga survei penonton, biro iklan, atau perusahaan yang ingin mempromosikan merek dagangannya. Bahkan, partai politik, ormas, organisasi keagamaan yang 
mengatasnamakan mewakili audience, juga berkepentingan merespons program acara televisi tersebut. Untuk itulah, Fairclough (1995) menyebut proses tersajinya program acara televisi ini sebagai "hegemonic struggle" (pertarungan hegemoni), sedangkan Fiske (1987) mengistilahkannya sebagai “an arena for struggle for meaning” (arena pertarungan makna), juga Littlejohn (1996) menyebutnya sebagai "a struggle among ideologies" (sebuah pertarungan di antara ideologi).

Media penyiaran televisi pada dasarnya merupakan sumber pengetahuan populer bagi kita untuk saling berhubungan dalam wilayah yang tidak terbatas. Televisi menjadi bagian dari, "prakondisi dan konstruksi selektif pengetahuan sosial yang kita gunakan untuk mempersepsi 'realitas' kehidupan orang lain, dan secara imajiner mengkonstruksi hidup kita dan mereka menjadi semacam 'keseluruhan dunia’ yang masuk akal bagi kita" (Hall, 1977:140).

Demikian juga menurut Irianto (2004), sajian acara televisi pada dasarnya mengakomodasi praktik sosial, yang senantiasa memproduksi representasi realitas sosial. Sebagai sajian acara televisi mampu memproduksi representasi realitas sosial, maka ia telah melibatkan interaksi dan negosiasi yang kompleks dan dinamis dari sejumlah pelaku. Interaksi dan negosiasi itu, bekerja melalui tiga tahap, yakni, tahap pra-penayangan, penayangan, maupun pasca-penayangan. Pada tahap pra-penayangan misalnya, akan melibatkan rumah produksi. Dalam rumah produksi ini di dalamnya terdapat para pelaku yang masing-masing mempunyai kepentingan, seperti pemimpin redaksi, produser, produser pelaksana, asisten produser pelaksana, koordinator liputan, bagian dokumentasi, bagian editor, bagian visual dan quality control, sekretaris redaksi dan tim peliput berita, bahkan juga narasumber berita. Baik pelaku yang mewakili rumah produksi maupun narasumber, pada dasarnya juga mempunyai kepentingan masing-masing. Sebut saja, kepentingan stasiun televisi, kepentingan rumah produksi, kepentingan biro iklan, kepentingan perusahaan pemasang iklan, serta kepentingan lembaga penentu survei penonton. Stasiun televisi tidak bisa berbuat banyak jika tidak mendapatkan hasil produksi dari rumah produksi. Demikian juga rumah produksi tidak bisa menjual hasil produksinya, jika hasil produksi tersebut tidak sesuai dengan kepentingan stasiun televisi. Stasiun televisi tidak bisa menayangkan sajian jika tidak mendapat dukungan sponsor atau pemasang iklan. Dukungan sponsor dan pemasang iklan dapat berjalan, jika tayangan tersebut mampu mengikat perhatian pemirsanya. Tayangan tersebut dinyatakan mampu mengikat 
perhatian pemirsanya, jika mendapat rekomendasi lembaga survei penonton tentang peringkat tinggi rendahnya (rating) sajian acara tersebut ditonton pemirsanya.

Sedangkan pada tahap pasca-penayangan, juga akan melibatkan kepentingan sejumlah institusi dan individu. Sebut saja, kepentingan Komisi Penyiaran Indonesia (KPI) yang mengatasnamakan institusi independen bentukan negara untuk memantau isi penyiaran sejumlah stasiun televisi. Bahkan pada tahap pasca-penayangan, sajian acara tersebut juga akan mendapat reaksi dari sejumlah institusi, seperti partai politik, organisasi masyarakat, organisasi keagamaan, atau lainnya. Dari sinilah, proses tarik menarik kepentingan - baik politik, ekonomi, maupun kepentingan yang lain -- di antara para pelaku tindakan yang memproduksi dan yang merespons sajian acara televisi akan terlihat. Proses tarik menarik kepentingan tersebut bisa berbentuk kerja sama atau bahkan berupa konflik (McQuail 2000).

Tarik menarik kepentingan itulah yang membentuk politik informasi media televisi. Katakanlah, ketika isi siaran televisi (di antaranya berupa tayangan program infotainment) dikuasai pemegang ekonomi politik informasi (political-economy of information), maka informasi menjadi alat kepentingan para subjek pelaku media untuk mencari keuntungan sebesar-besarnya. Para penguasa ekonomi ini kemudian berperan menjadi perumus realitas (definer of reality). Artinya, ideologi atau kepentingan para subjek pelaku media akan menelusup melalui tayangan yang diproduksi dan direproduksinya. Apalagi, tayangan yang diproduksi dan direproduksi stasiun televisi tersebut merupakan salah satu teks utama televisi. Sebagai salah satu teks, tayangan televisi bukan hasil rangkaian realitas, melainkan representasi yang terseleksi dan terkonstruksi serta menjadi bagian yang turut membentuk realitas (Barker,2000; Bennet, 1982; Berger dan Luckman, 1990; dan Piliang, 2005).

Terseleksi dan terkonstruksinya realitas tersebut, ditentukan oleh pengetahuan dan tindakan para subjek pelaku tindakan yang terlibat dalam media. Dengan demikian, kenyataan subjektif yang berasal dari pengetahuan dan tindakan subjek pelaku media akan lebih mewarnai sajian acara televisi. Di sisi lain, para pelaku media secara subjektif juga dapat mengubah kategori persepsi dan apresiasi yang mengendalikan berbagai pandangannya tentang realitas sosial melalui tayangan acara televisi tersebut (Severin \& Tankard 2005 dan Irianto,2004).

Dengan demikian, dapat dikatakan bahwa tersajikannya program tayangan infotainment pada dasarnya lebih ditandai oleh praktik-praktik sosial para pelaku 
dalam rangka berinteraksi dan bernegosiasi dengan pelaku yang lain. Dalam praktikpraktik sosial para pelaku itulah, sejumlah pelaku melalui relasi-relasi yang ada akan bersaing, berjuang, dan saling mengalahkan, yang secara langsung maupun tak langsung menandai bekerja dan berkontestasinya kekuasaan. Istilah kekuasaan dalam hal ini secara sederhana bisa diartikan sebagai kemampuan individu atau institusi untuk mengendalikan, mempengaruhi, dan membuat pelaku yang lain melakukan sesuatu (Saifuddin, 2005:360-361). Atau dengan kata lain, bekerja dan berkontestasinya kekuasaan dalam hal ini tidak dilihat sebagai gambaran yang menampilkan para kontestan dalam keonstelasi yang statis (Pradipto, 2007). Ia lebih dilihat sebagai proses interaksi dan negosiasi yang di dalamnya kekuasaan bekerja dan berpengaruh dalam konteks tertentu.

\section{Simpulan}

Kesenian tradisional-terutama seni budaya wayang-dibutuhkan revitalisasi Revitaliasi kesenian tradisional menjadi salah satu strategi yang efektif untuk meningkatkan ketahanan budaya bangsa, bahkan pembangunan nasional idealnya bertitik-tolak dari upaya-upaya pengembangan kesenian tradisional yang mampu melahirkan "nilai-tambah kultural”. Seni budaya wayang selama ini dikenal sebagai kesenian yang hanya mempertahankan pakem-pakem yang kaku tetapi kurang beradaptasi dengan perkembangan zaman dan tuntutan audience-nya. Pakem-pakem itu memang tetap diperlukan, karena ia berakar dalam budaya masyarakat, namun ia dimungkinkan untuk dekomposisi, rekonstruksi, rekoreografi, renovasi, revitalisasi, refungsionalisasi, disertai improvisasi dengan aneka hiasan. Melalui penayangan di acara televisi, keberada seni budaya wayang akan menjadi efektif untuk meningkatkan ketahanan budaya bangsa, bahkan pembangunan nasional idealnya bertitik-tolak dari upaya-upaya pengembangan kesenian tradisional yang mampu melahirkan "nilai-tambah kultural".

\section{Daftar Pustaka}

Barker, Chris. 2003. Cultural Studies: Theory and Practice (2nd edition). London: SAGE Publishers

Berger, Peter dan Thomas Luckman. 1990. Tafsir Sosial Atas Kenyataan: Sebuah Risalah Tentang Sosiologi Pengetahuan (terjemahan). Jakarta: LP3ES 
Fairclough, Norman. 1994. Critical Discourse Analysis. New York: Longman Group Limited.

Fiske, John. 1987. Television Culture. London: Routledge

Hall, Stuart. 1976. "The Centrality of Culture: Notes on the Cultural Revolutions of Our Times" dalam K. Thompson (ed.) Media and Cultural Regulations. London: Sage.

Irianto, Agus Maladi. 2014. Media dan Kekuasaan: Antropologi Membaca Duni Kontemporer. Semarang: Pustaka Mandiri

Littlejohn, Stephen W. 1994. Theories of Human Communication. Belmont: Communication. Wadworth Publishing Company

McQuail, Dennis. 2000. McQuail's Mass Communication Theory. London: Sage Publications

Piliang, Yasraf Amir. 2004. Posrealitas, Realitas Kebudayaan dalam Era Posmetafisika. Bandung: Jalasutra

Pradipto, Y. Dedy. 2007. Belajar Sejati VS Kurikulum Nasional: Kontestasi Kekuasaan dalam Pendidikan Dasar, Yogya: Kanisius.

Saifuddin, Achmad Fedyani. 2004. Antropologi Kontemporer. Suatu Pengantar Kritis Mengenai Paradigma. Jakarta: Prenada Media

Saverin, Werner J. \& James W. Tankard. 2005. Teori Komunikasi: Sejarah, Metode, dan Terapan di Dalam Media Massa. Jakarta: Prenada Media.

Sen, Krisna dan David T.Hill. 2001. Media, Budaya dan Politik di Indonesia. Jakarta: PT Media Lintas Inti Nusantara 